\author{
University of California \\ Ernest O. Lawrence \\ Radiation Laboratory
}

MASIR

\title{
HIGH-SPEED MICROWAVE PHASE SHIFTERS USING VARACTOR DIODES
}

Livermore, California 


\section{DISCLAIMER}

This report was prepared as an account of work sponsored by an agency of the United States Government. Neither the United States Government nor any agency Thereof, nor any of their employees, makes any warranty, express or implied, or assumes any legal liability or responsibility for the accuracy, completeness, or usefulness of any information, apparatus, product, or process disclosed, or represents that its use would not infringe privately owned rights. Reference herein to any specific commercial product, process, or service by trade name, trademark, manufacturer, or otherwise does not necessarily constitute or imply its endorsement, recommendation, or favoring by the United States Government or any agency thereof. The views and opinions of authors expressed herein do not necessarily state or reflect those of the United States Government or any agency thereof. 


\section{DISCLAIMER}

Portions of this document may be illegible in electronic image products. Images are produced from the best available original document. 
per is being distributed in Microcard

form as a preprint.

UNIVERSITY OF CALIFORNIA

Lawrence Radiation Laboratory

Livermore, California

Contract No. W $-7405-$ eng -48

\section{HIGH-SPEED MICROWAVE PHASE SHIFTERS \\ USING VARACTOR DIODES}

A. L. Gardner

Ronald S. Hawke

July 24, 1964 
High-Speed Microwave Phase Shifters Using Varactor Diodes* Andrew L. Gardner and Ronald S. Hawke

\author{
Law \\ Livermore, California \\ July 24,1964
}

\begin{abstract}
A reflection-type microwave phase shifter is described which is similar to the units developed by Hardin et al., ' and employs the voltage-variable capacitance of varactor diodes as the adjustable element. The "pill-type" diodes tune their associated circuit through a resonance to produce phase shifts of over 90 degrees. With proper adjustment of the coupling - a simple procedure - the output amplitude is made essentially constant. The use of two diodes in RF series bucking configuration permits higher-power operation, although the unit is essentially a low-power device.
\end{abstract}

\title{
INTRODUCTION
}

Microwave phase shifters that can be tuned electrically and have the advantage of high speed have been noted earlier. In at least two instances phase shifters with varactor diodes have been described, ${ }^{1,2}$ although in the one case ${ }^{2}$ coaxial transmission lines were used in the VHF range.

* Work performed under the auspices of the U. S. Atomic Energy Commis sion. 
Hardin et al. ' used various waveguide circuits which incorporated two varactor-diode terminations. Although sizable phase shifts were reported for these transmission-type units (from $41^{\circ}$ at $9 \mathrm{Gc}$ to over $180^{\circ}$ at $1 \mathrm{Gc}$ ), apparently no specific means was provided to obtain an output of optimally constant amplitude.

We describe here a simple reflection-type phase shifter in which "pilltype" varactor diodes form a part of a resonant circuit in a waveguide in a manner similar to that of Hardin et al. ${ }^{1}$ We also describe a method of matching which renders the amplitude essentially constant. With such a device, phase shifts that are variable over $144^{\circ}$ have been obtained at 9 Gc with a constant reflection loss of $3.5 \mathrm{db}$. Since the variable capacitance of the diodes is used to tune the associated circuit near a resonant frequency, this phase shifter is a rather narrow-band device. However, this is compensated by the ease with which the circuit resonance may be tuned to any desired frequency and matched for constant amplitude of the reflected wave. The inherently fast response and constant amplitude output of this phase shifter make it particularly suitable for some types of phase measurements in circuits using a $\mathrm{CW}$ microwave source at a fixed frequency. Such devices have shown their utility in this Laboratory in null-type bridges at $24 \mathrm{Gc}$ and at $9 \mathrm{Gc}$. In the latter case, phase shifts of less than $0.003^{\circ}$ were measured.

The phase shifter consists of three basic elements: (1) the varactor diodes which are mounted across a section of waveguide that is interposed between (2) a slide-screw tuner and (3) a shorting plunger. As noted below, the slide-screw tuner may be unnecessary if the varactors are suitably positioned. For least frequency sensitivity, the distances between the components should be small - ideally the shorting plunger should be capable of 
moving toward the varactors until the lowest order resonance is reached (about one-half of a guided wavelength for the cases described).

\section{MOUNTING THE VARAGTORS}

Figure 1 shows an end view of a single varactor positioned in a section of $8-\mathrm{mm}$ waveguide. The screw, which provides an electrical ground, holds the varactor tight against a copper disk. The disk and the wire feedthrough are insulated from the waveguide by a mica disk and the enamel on the wire. To prevent excessive radiation of microwave power out via the feedthrough, the insulating disk should be very thin or, better, the feedthrough system should be long enough to form a resonant choke. A more elaborate choke system may be used, of course.

The dual-varactor mount sketched in Fig. 2 has a feedthrough wire that is perpendicular to the microwave E-field. The radiation losses with this arrangement are negligible. In this type of mount the two diodes present a series-bucking configuration to the microwave E-field; thus, with matched diodes the increase in the capacitance of one diode, due to the presence of the rf field, is equal, to first order, to the decrease in the capacitance of the other diode. Harmonic generation is hence reduced. Furthermore, because the rf voltage across each diode is only half of the total $r f$ voltage, a higher power can be accommodated before the voltage becomes comparable to the bias voltage. Another advantage of this style of mount is that it has a lower input capacitance of the bias-voltage lead, which makes faster modulation possible.

The dual-varactor mount shown in Fig. 3 permits a lateral displacement of the varactor stack. In some cases this can obviate the need for the slidescrew tuner and result in a device with less frequency sensitivity. In this 
mount the small diameters of the supporting tubes fairly well minimize the stray shunt capacitance across the diodes.

\section{METHOD OF TUNING}

A simple way of tuning is to use an oscilloscope to view the amplitude of the reflected signal, while applying a fraction of the sawtooth sweep voltage from the oscilloscope to back-bias the varactor diodes. It is convenient, but not necessary, to use a chopped CW microwave source, which then provides a continuous indication of the "no-signal" baseline.

With the slide screw entirely withdrawn, the shorting plunger position is varied until resonance is achieved near the center of the range of varactor sweep voltage, i.e., until a dip in the observed signal is located and moved to the center of the trace. If possible, the plunger should be further inserted $\lambda_{g} / 2$ to achieve a resonance at a lower-order mode. The slide screw is next inserted to successive depths, and positioned longitudinally with each increase in depth, until the position is found at which the signal amplitude barely dips to zero at the center of the trace. The screw should be inserted no farther than is necessary to obtain the dip to zero. In this condition, a plot of impedance or admittance as a function of varactor voltage passes through the center of a Smith chart, i.e., at resonance the tuned circuit is critically coupled. The objective, of course, is that such a plot encircle the center of the chart at a constant, preferably large, radius. The final tuning follows one of the two procedures described below.

Case 1: Initially undercoupled resonant circuit. In this case, further insertion of the slide screw moves the position of the signal minimum toward the left, i.e., toward the lower reverse voltages on the varaetor and therefore to higher varactor capacitance. This indicates that be- 
fore the slide screw was inserted an impedance plot would not have encircled the center of the Smith chart and that optimum tuning will be achieved with still deeper penetration of the screw. To produce minimum amplitude variation of the reflected signal, the depth of the screw should be increased and the longitudinal position should be slightly adjusted, if necessary. A test will show that small longitudinal movements of the screw about its proper position will "pivot" the observed pattern about the original resonance position.

Case 2: Initially over-coupled resonant circuit. In this case, further insertion of the slide screw moves the position of the signal minimum toward the right, i.e., to lower varactor capacitance. This shows that before the screw was inserted an impedance plot would have partially encircled (would have been concave toward) the center of the Smith chart. For final tuning in thio case, the screw sudy be completely withdrawn and then reinserted at a position roughly $\lambda_{g} / 4$ away to a depth that will produce a minimum amplitude change in the reflected signal.

For the few varactors tested, Case 1 was found to be the normal situation for diodes mounted in the center of the guide.

To some extent at least, the device may be matched without the slide screw by offsetting the varactor stack (Fig. 3) an appropriate distance toward the narrow wall of the guide. This results in a greater useful bandwidth for a given tuning and also in a higher reflection coefficient. With the diodes initially offset to achieve essentially a constant amplitude of the reflected wave, the broadened resonance naturally will be more difficult to recognize. To adjust the shorting plunger to the proper position for resonance in such a case, it may be necessary to "observe" the rate of phase change of the reflected wave, as the back-bias voltage is changed. 


\section{PERFORMANCE}

The measurements shown here were made with approximately one milliwatt of rf power at X-band and with RGA-type VD-Ilo Gallium arsenide varactor diodes. The data shown in Figs. 4 and 6 were taken with the same two varactors in a mount of the type sketched in Fig. 3. These particular diodes had junction capacitances of $0.38 \mathrm{pf}$ and $0.34 \mathrm{pf}$ at -6 volts bias and breakdown voltages of about -9 volts. Figure 4 shows two Smith chart plots of the system impedance $e^{*}$ as a function of the applied bias voltage with the varactor stack positioned in the center of the guide. In this instance, the shorting plunger was originally set to give equal amplitude reflection at 0 and 8 volts bias before the slide screw was inserted. This placed the dip of the resonance at nearly 3 volts rather than at the mid-range value of 4 volts. The final range of $110^{\circ}$ of phase shift was obtained with measured VSWR values ranging from 7.03 to 7.12 , representing a loss of about $2.5 \mathrm{db}$ upon reflection and an output power variation of less than $1 \%$. The amount of phase shift per volt of bias decreases as the bias is increased. This nonlinearity may be substantially reduced (at a sacrifice of some of the phase-shift range) by initially offsetting the resonance toward the higher bias voltages. Figure 5 gives an example of this.

An indication of the useful frequency range that can be obtained with a fixed adjustment of the shorting plunger is given in Fig. 6. For these measurements the varactor stack was offset toward the narrow wall of the guide enough to allow the slide screw to remain completely withdrawn, i.e., the dip

\footnotetext{
* Both plots are made with the same plane of reference. This plane is a whole number of guided half-wavelengths ahead of the varactor stack before the slide screw is inserted.
} 
at resonance was very slight but extended over a wide range of bias voltage. Over a range of $400 \mathrm{mc}$ (about $4.5 \%$ of the center frequency), the available phase shift is at least half of its peak value. The peak of $61^{\circ}$ is appreciably lower than the $110^{\circ}$ obtained with the varactors centered, but the loss upon reflection is reduced.

The rf-power limitations of the dual varactor arrangement have not been measured, although in cursory checks with the varactors mounted off center (as for the data in Fig. 6), $45 \mathrm{mw}$ at $9 \mathrm{Gc}$ and $125 \mathrm{mw}$ at $10 \mathrm{Gc}$ caused no increase in losses with the back-bias voltage set at the extreme values of 0 volts and 8 volts. However, at these extremes of the bias range, a few milliwatts was enough to alter by 1 ma the average current drawn from (or delivered to) a bias supply with a dc impedance of $10 \mathrm{k} \Omega$.

\section{SUMMARY}

With proper coupling a remarkably constant amplitude of the reflected. wave may be obtained from this device. This is an important feature for accurate null-type phase measurements in some microwave circuits.

Although the varactor diodes impose an rf power limitation on this type of circuit, the use of two diodes in series-bucking configuration extends the power handling capability and at the same time reduces the problem of rf leakage from the bias input. 
$-8-$

\section{REFERENCES}

${ }^{1}$ R. H. Hardin, E. J. Downey, and J. Munushian, Proc. Inst. Radio

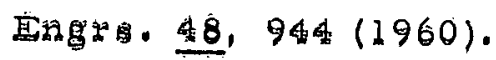

${ }^{2}$ R. L. Orrick, Jr., Electronic Industries 21, 116 (1962). 


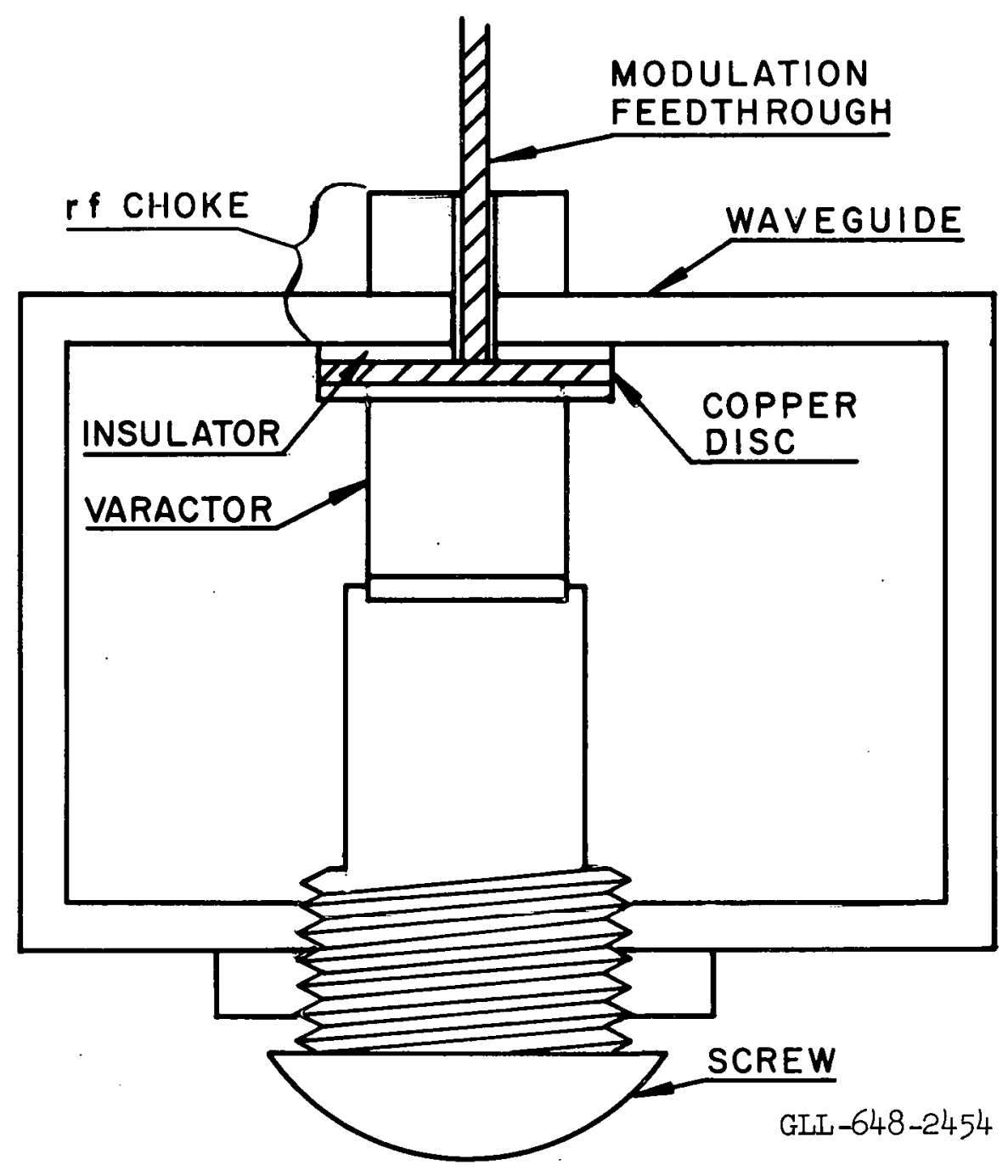

Fig. 1. Single-varactor mount. 


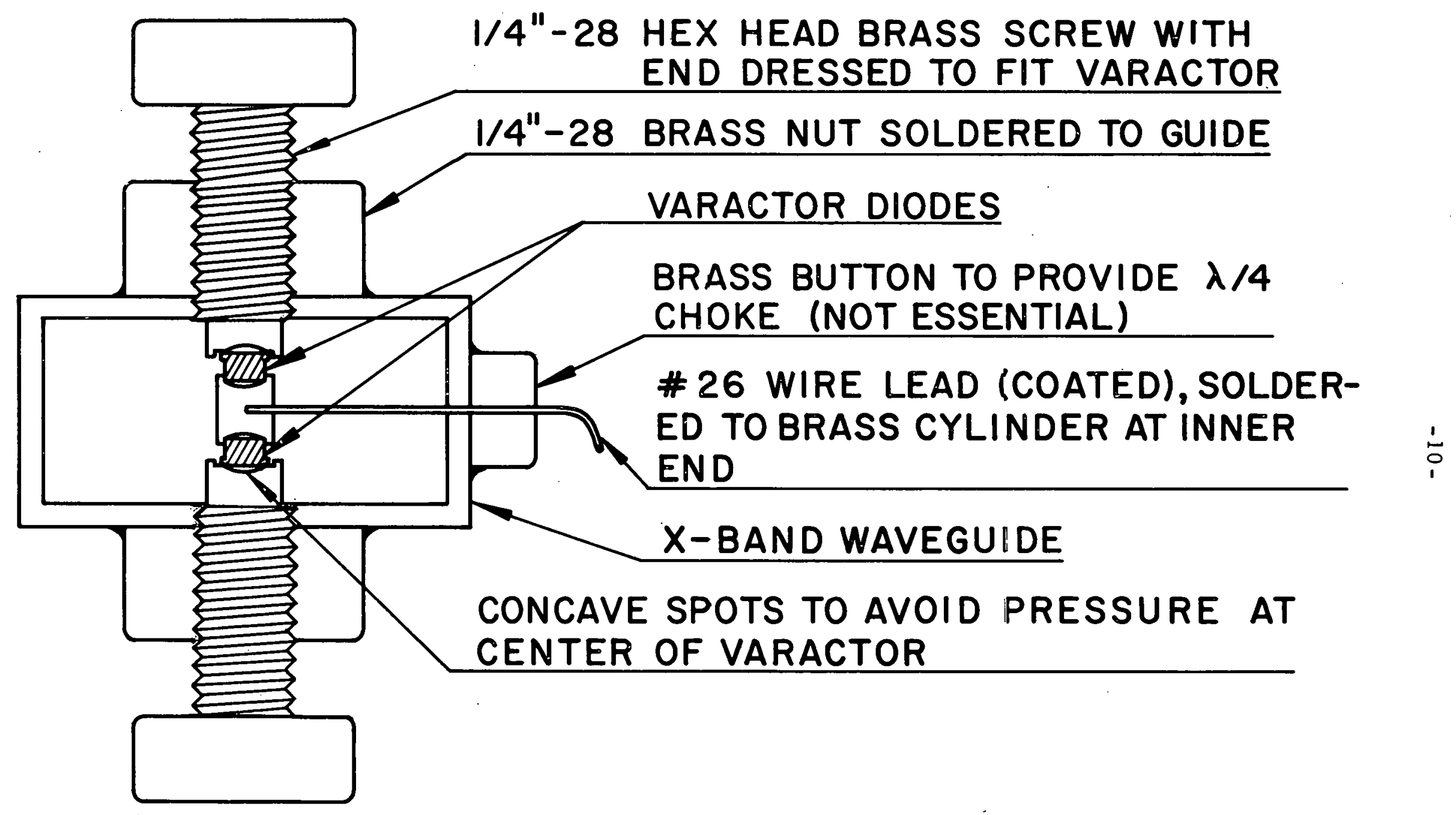




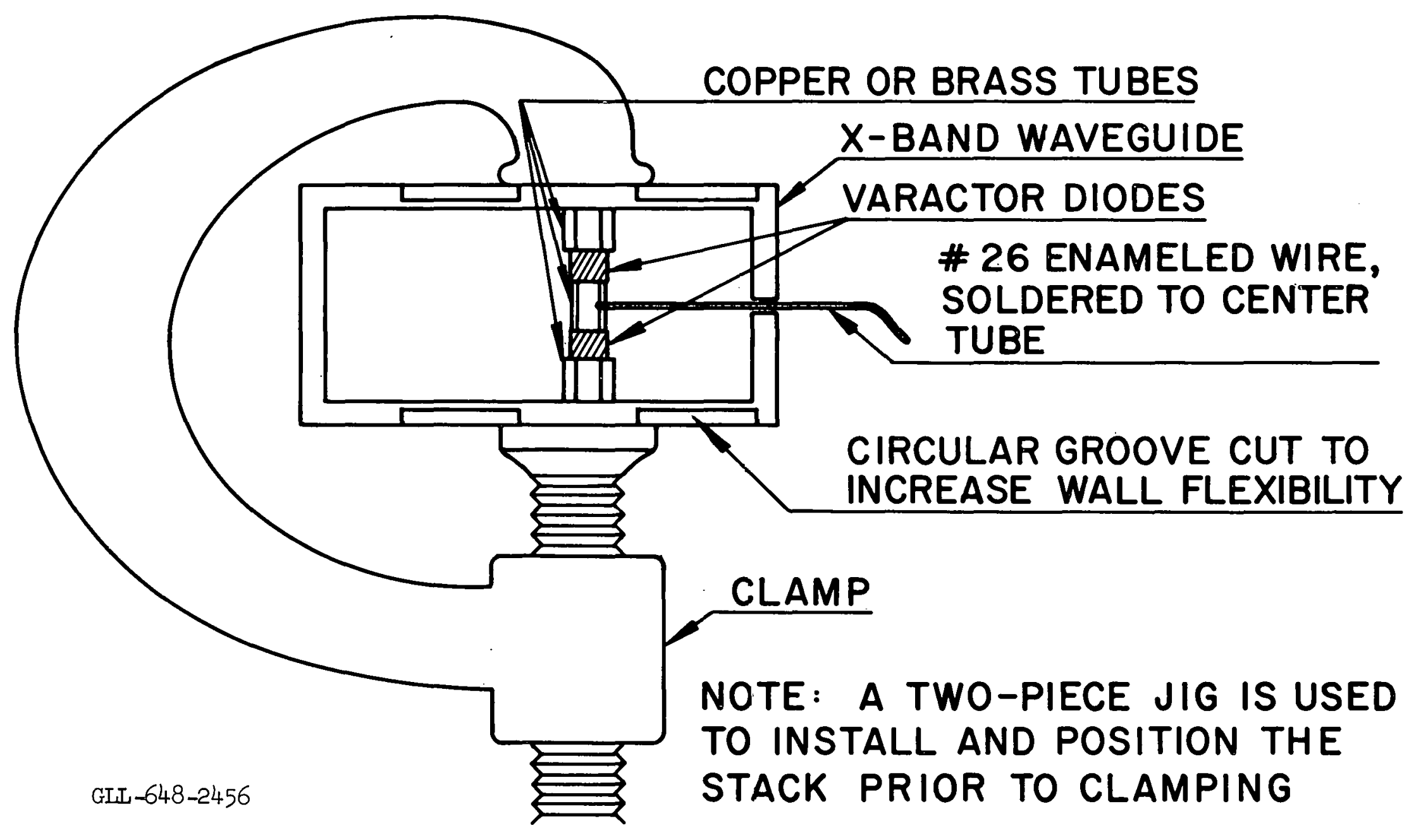

Fig. 3. Cross section of a dual mount that permits off-center positioning of varactor diodes. 
- NO TUNING AHEAD OF VARACTOR DIODES

- SLIDE - SCREW ADJUSted (NUMBERS SHOW VARACTOR BIAS VOLTAGE)

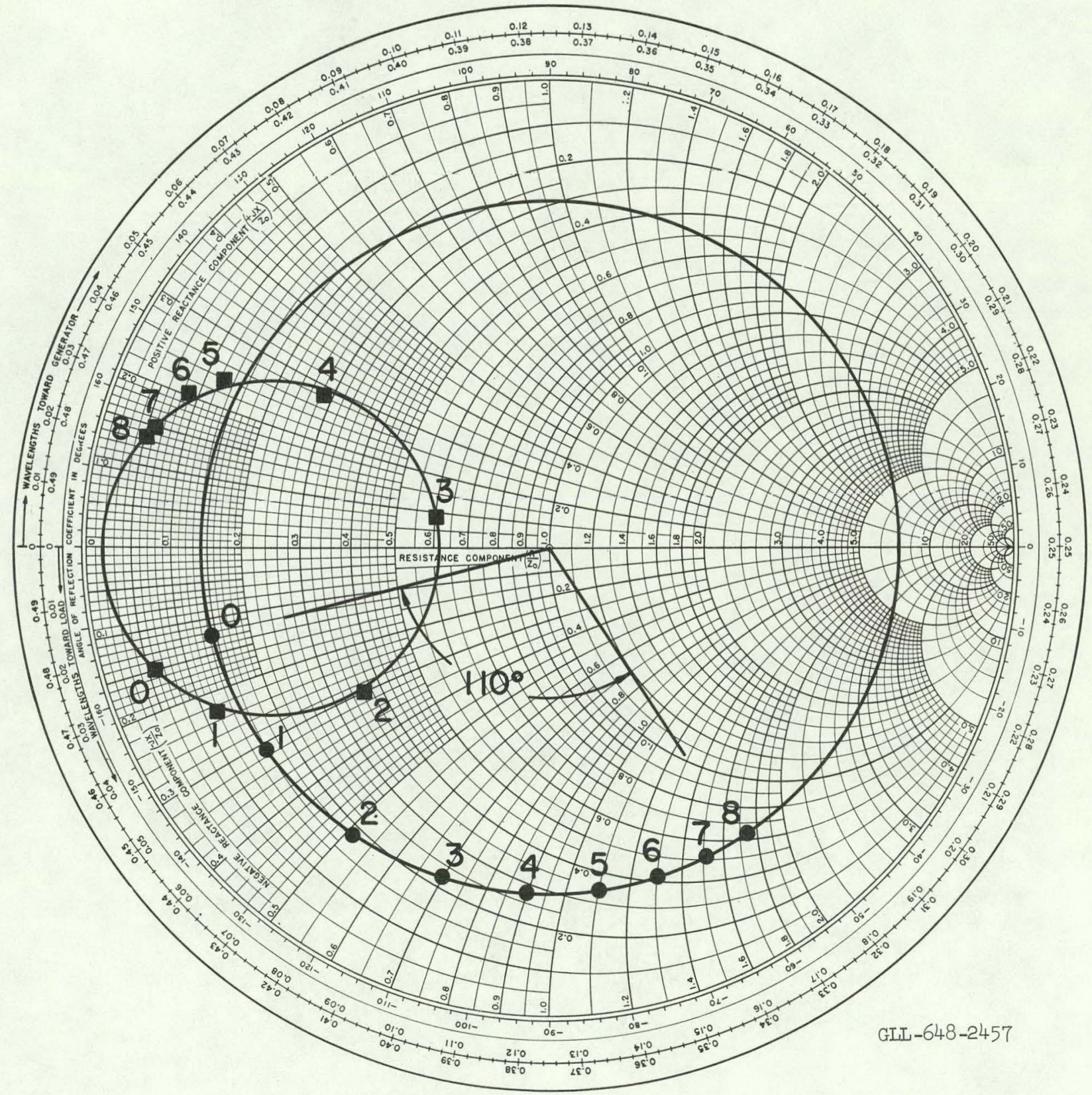

Fig. 4. Impedance plots with varactor diodes mounted at the center of the waveguide. 


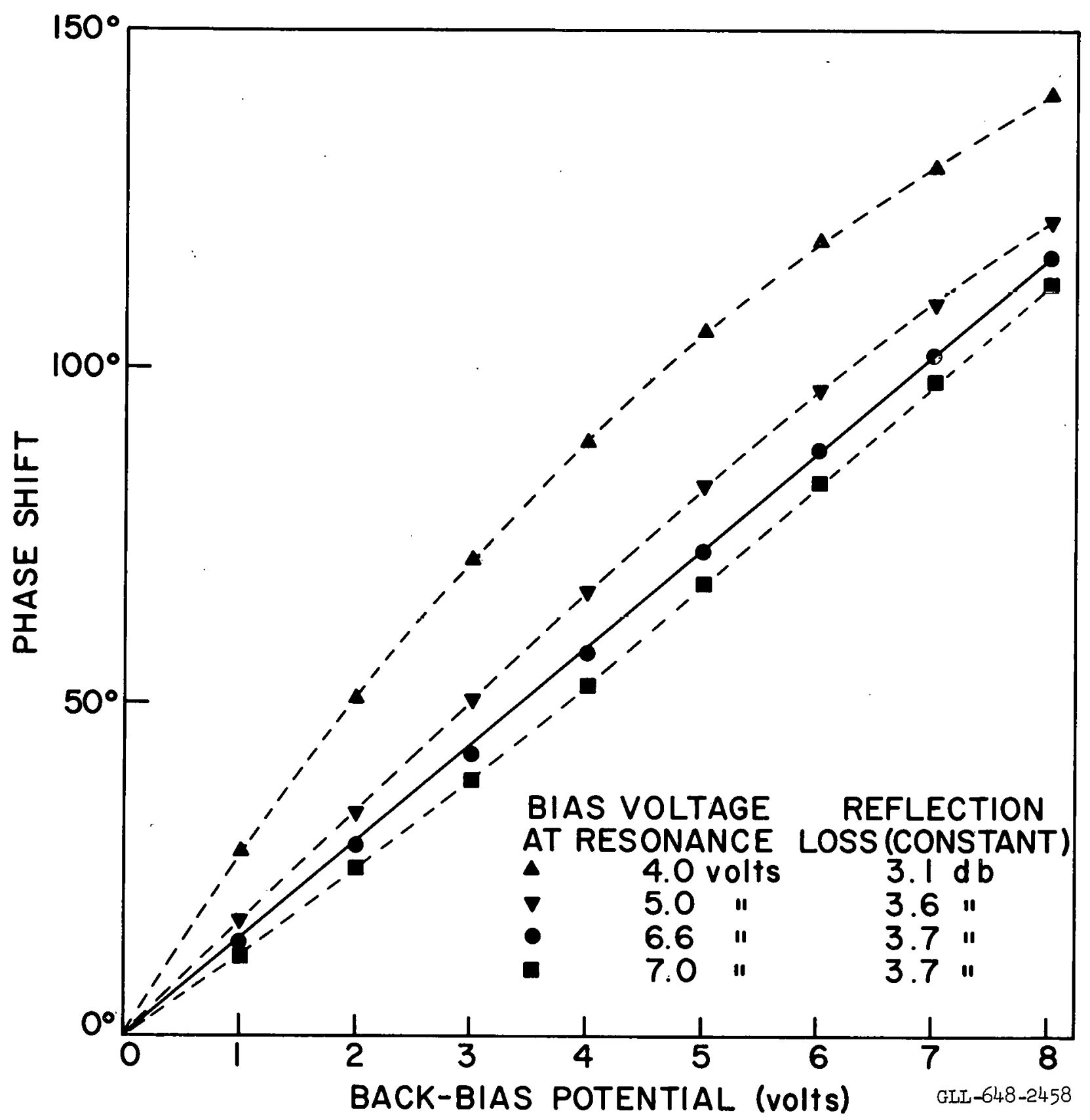

Fig. 5. An example of obtaining approximately linear phase shift vs bias voltage by off-setting the resonance toward higher bias voltages. 


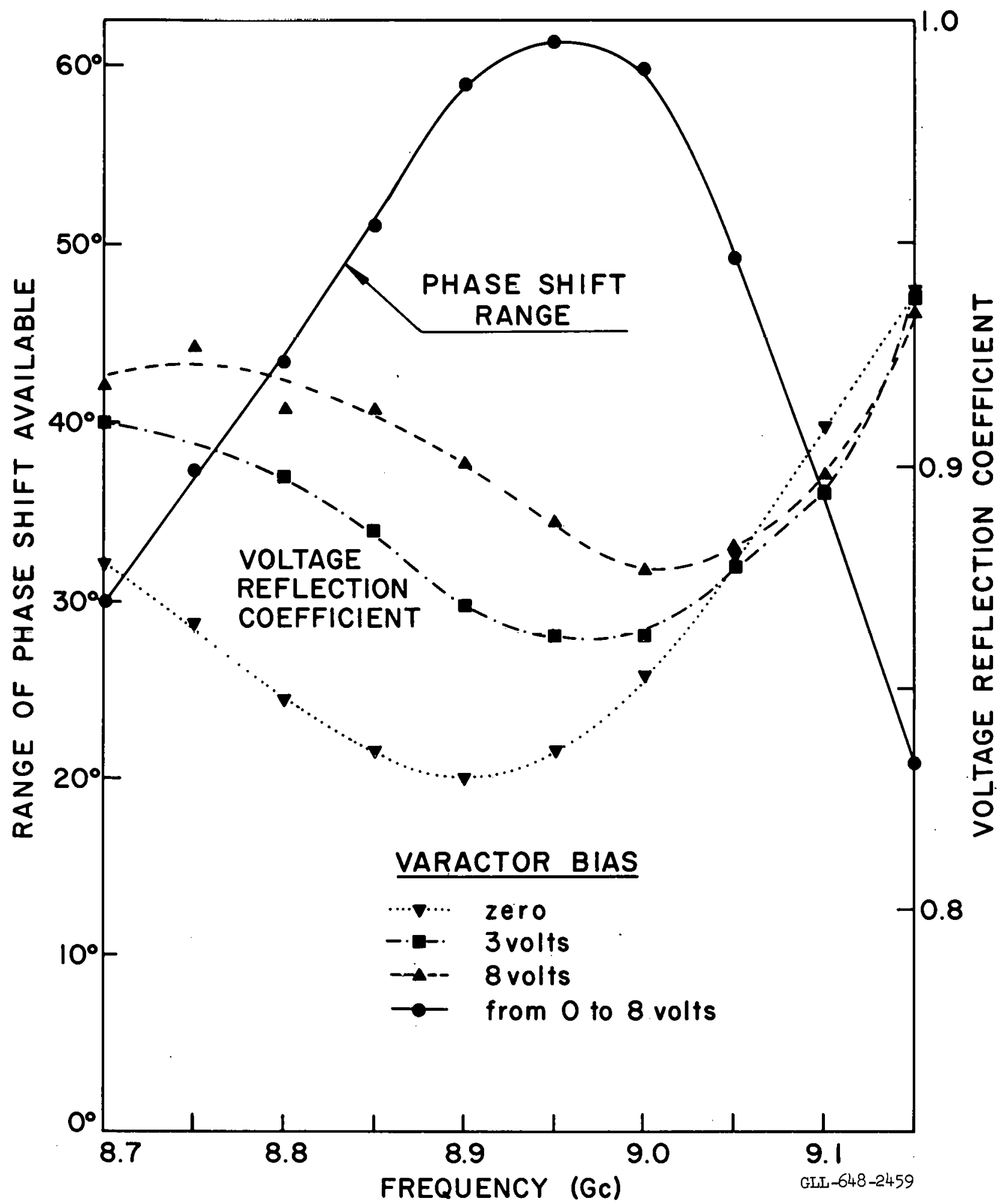

Fig. 6. Phase-shift range and reflection coefficient vs frequency for a mount with off-center matching. 
This report was prepared as an account of Government sponsored work. Neither the United States, nor the Commission, nor any person acting on behalf of the Commission:

A. Makes any warranty or representation, expressed or implied, with respect to the accuracy, completeness, or usefulness of the information contained in this report, or that the use of any information, apparatus, method, or process disclosed in this report may not infringe privately owned rights; or

B. Assumes any liabilities with respect to the use of, or for damages resulting from the use of any information, apparatus, method or process disclosed in this report.

As used in the above, "person acting on behalf of the Commission " includes any employee or contractor of the commission, or employee of such contractor, to the extent that such employee or contractor of the Commission, or employee of such contractor prepares, disseminates, or provides access to, any information pursuant to his employment or contract with the Commission, or his employment with such cortractor. 